University of Nebraska - Lincoln

DigitalCommons@University of Nebraska - Lincoln

Bureau of Sociological Research - Faculty

Publications

Bureau of Sociological Research (BOSR)

February 2001

\title{
History of Affective Disorder and the Temporal Trajectory of Fatigue in Rheumatoid Arthritis
}

Judith Fifield Ph.D.

The University of Connecticut School of Medicine

Julia McQuillan

University of Nebraska - Lincoln, jmcquillan2@Unl.edu

Howard Tennen

The University of Connecticut School of Medicine

T. Joseph Sheehan

The University of Connecticut School of Medicine

Susan Reisine

The University of Connecticut School of Dental Medicine

See next page for additional authors

Follow this and additional works at: https://digitalcommons.unl.edu/bosrfacpub

Part of the Sociology Commons

Fifield, Judith Ph.D.; McQuillan, Julia; Tennen, Howard; Sheehan, T. Joseph; Reisine, Susan; Hesselbrock, Victor; and Rothfield, Naomi, "History of Affective Disorder and the Temporal Trajectory of Fatigue in Rheumatoid Arthritis" (2001). Bureau of Sociological Research - Faculty Publications. 1.

https://digitalcommons.unl.edu/bosrfacpub/1

This Article is brought to you for free and open access by the Bureau of Sociological Research (BOSR) at DigitalCommons@University of Nebraska - Lincoln. It has been accepted for inclusion in Bureau of Sociological Research - Faculty Publications by an authorized administrator of DigitalCommons@University of Nebraska - Lincoln. 


\section{Authors}

Judith Fifield Ph.D., Julia McQuillan, Howard Tennen, T. Joseph Sheehan, Susan Reisine, Victor

Hesselbrock, and Naomi Rothfield

This article is available at DigitalCommons@University of Nebraska - Lincoln: https://digitalcommons.unl.edu/ 


\title{
History of Affective Disorder and the Temporal Trajectory of Fatigue in Rheumatoid Arthritis
}

\author{
Judith Fifield, Ph.D. \\ The University of Connecticut School of Medicine \\ Julia McQuillan, Ph.D. \\ The University of Nebraska at Lincoln \\ Howard Tennen, Ph.D. and T. Joseph Sheehan, Ph.D. \\ The University of Connecticut School of Medicine \\ Susan Reisine, Ph.D. \\ The University of Connecticut School of Dental Medicine \\ Victor Hesselbrock, Ph.D. and Naomi Rothfield, M.D. \\ The University of Connecticut School of Medicine
}

\begin{abstract}
This study examines whether the general level and rate of change of fatigue over time is different for those rheumatoid arthritis (RA) patients with and those without a history of affective disorder $(A D)$. Four hundred fifteen RA patients from a national panel had yearly telephone interviews to obtain fatigue and distress reports, and a one-time semistructured assessment of the history of depression and generalized anxiety disorder. Growth-curve analysis was used to capture variations in initial fatigue levels and changes in fatigue over 7 years for those with and without a history. RA patients with a history of major AD reported levels of fatigue that were $10 \%$ higher than those without a history in the 1st year of the study. Their fatigue reports remained elevated over 7 years. Further analysis showed that the effects of a history of AD on fatigue are fully mediated through current distress, although those with a history had a significantly smaller distress-fatigue slope. Thus, a history of AD leaves RA patients at risk for a 7-year trajectory of fatigue that is consistently higher than that of patients without a history. The elevation in fatigue reports is, at least in part, a function of enduring levels of distress.
\end{abstract}

(Ann Behav Med 2001, 23(1):34-41)

\section{INTRODUCTION}

Fatigue is a common and frequently debilitating problem for people with rheumatoid arthritis (RA). Studies of fatigue have focused on the underlying inflammatory process (1) and fatigue's association with increased disease activity (2), sleep disturbance, pain, length of time with the diagnosis of RA, depressive symptoms, daily stressors, and functional disability

The work was supported by a Clinical Science Grant from the National Arthritis Foundation. This article was presented at the XIV World Congress of Sociology, Montreal, July 26 through August 1, 1998.

Reprint Address: J. Fifield, Ph.D., University of Connecticut Health Center, MC-2918, Farmington, CT 06030.

(C) 2001 by The Society of Behavioral Medicine.
(3-8). To date, this area of research has been limited to predictors measured either concurrently or in close temporal proximity with the fatigue report.

Although concurrent predictors are essential, a growing body of research suggests that an important, but rarely examined, predictor of physiological symptoms such as fatigue is the individual's history of affective disorder (AD) (9-14). The pathway from $\mathrm{AD}$ to physiological outcome is not known (15). It has been suggested that the experience of $\mathrm{AD}$, such as major depression (MD), is associated with alterations at the cellular level that remain abnormal even in remission, thus creating a long-term risk for worse outcomes long after the episode $(16,17)$. For instance, altered biochemical processes following MD may explain sustained sleep deprivation and thus higher levels of fatigue in some patients (18). Alternatively, a link between past $\mathrm{AD}$ and symptom reports may be through an enduring personality characteristic such as neuroticism $(\mathrm{N}) . \mathrm{N}$, which is common among individuals with a history of $\mathrm{AD}$ (19), is also associated with elevated symptom reporting (20) and a vulnerability to negative emotion. Thus, the focus in this literature is on factors associated with $\mathrm{AD}$ that create long-term consequences for patients.

Our previous work examining the association between a history of $\mathrm{AD}$ (11) and the future experience of symptoms of RA was cross-sectional. To fully evaluate the sustained effect on fatigue, we asked whether those with such a history experience a different course or trajectory of fatigue over time. The intent of this analysis is to begin to explore whether the general level and rate of change of fatigue over time (the fatigue trajectory) is different for those with and those without a history of AD.

\section{METHOD}

\section{Participants}

The National Rheumatoid Arthritis Study is a prospective panel study that completed its 10th and final year in 1997 through 1998. The panel of 988 patients with classical or definite RA (21) was recruited from a national, random sample of board-certified rheumatologists (details of the recruitment are 
published elsewhere) (11). At the close of their 8th-year interview, the 508 patients remaining in the panel were asked if they would be interested in participating in an additional interview about their emotional and physical well-being. A total of 462 (91\%) agreed to the follow-up interview, and 415 (90\%) completed it. They were largely upper middle age $(M=58, S D=$ 9.7), married (68\%), out of the labor force (65\%), women (83\%), which is consistent with the 3:1 prevalence of RA among middle-age women compared to men and the relatively low employment rate found in similar samples of RA patients (22).

\section{Procedures}

The telephone interview lasted approximately $30 \mathrm{~min}$. Current and lifetime Diagnostic and Statistical Manual of Mental Disorders (4th ed. [DSM-IV]) (31) psychiatric diagnoses of MD and generalized anxiety disorder (GAD) were obtained using the Semi-Structured Assessment for the Genetics of Alcoholism (SSAGA) (23). The SSAGA, based on the Diagnostic Interview Survey (DIS) (24), is suitable for either telephone or face-to-face administration by lay interviewers (25). Although it offers the same reliability and validity as the DIS (26), the SSAGA offers certain options that make it attractive for use in the arthritis population, including the ability to link episodes of MD or GAD to comorbidities and flares, as well as drug use, alcohol use, or both.

Interviewers completed approximately $20 \mathrm{hr}$ of SSAGA training. They were supervised by a clinical psychologist, and every interview was edited for accuracy by a research staff member with a master's degree in psychology and several years of experience with the development of the interview.

\section{Measures}

Demographic characteristics. Demographic variables include age, sex, education, family income, marital status, and working status.

Fatigue associated with RA. Fatigue associated with RA was measured by asking patients, "On a scale of 0 to 100 , with 0 being no fatigue at all and 100 being the most fatigue possible, how much arthritis fatigue did you feel in the past week?" Comparable scales have been employed successfully in other studies of RA (27). This indicator of fatigue was used at each yearly interview from Years 2 through 8 . Thus, we were able to trace fatigue reports over 7 years.

Distress. Distress was measured with the Center for Epidemiological Studies Depression Scale (CES-D) (28). Although the CES-D scale was originally developed to measure depressive symptoms in community populations, recent concerns about its discriminant validity suggest that researchers should interpret scores more broadly as indicators of distress $(29,30)$.

The CES-D is a 20-item questionnaire that reflects various aspects of depression, including depressed mood, feelings of guilt and worthlessness, loss of appetite, and sleep disturbance. It yields a single summary score that ranges from 0 to 60 . Good reliability and validity have been reported (28). The alpha reliability coefficient of the scale in this sample was .75 .

Diagnosis of AD. DSM-IV (31) criteria to qualify for a diagnosis of MD include (a) depressed mood or loss of interest and pleasure in things that the individual usually cared about or enjoyed every day or nearly every day for 2 weeks or more at some time in the past while experiencing impaired role functioning, and (b) four of eight symptoms: problems with appetite, sleep, fatigue, energy, interest, self-worth, cognition, or suicidal ideas. The episode could not be due to injury, illness, medication or alcohol, childbirth, or the loss of a loved one within certain time parameters. A diagnosis of current MD required that symptoms occurred within 3 weeks of the interview, whereas a diagnosis of lifetime MD required that the symptoms occurred anytime in the past but not the past 3 weeks.

$D S M-I V$ criteria for a GAD include (a) excessive anxiety and worry for 6 months; (b) difficulty controlling worry; and (c) at least three of the following six symptoms experienced nearly every day during the episode: restlessness, being easily fatigued, difficulty concentrating or mind going blank, irritability, muscle tension, sleep disturbance. Symptoms cannot be due to the direct effects of a substance or medical condition, they must manifest themselves in role impairment, and they cannot be exclusively coincident with mood disorder. Current GAD required all of these criteria within the 6 months preceding the interview, whereas lifetime GAD required the same criteria for 6 months in the past prior to that time.

$D S M-I V$ does not include criteria for a comorbid condition. The scoring of both MD and GAD requires assigning a case that meets criteria for both conditions to the MD diagnosis. However, because the emotional and physical outcomes of individuals with both MD and GAD are less positive (32), we classified people who met full criteria for both MD and GAD as comorbid. When the comorbid category is considered in the following analyses, the number of "pure MD" and "pure GAD" is adjusted to reflect those who belong in the comorbid category.

\section{Statistical Analysis: Growth-Curve Models}

Growth-curve analysis (33-40) was used to capture variations in initial fatigue levels and changes in fatigue over time and to determine if a history of AD influences fatigue's level and temporal trajectory. We chose Hierarchical Linear Models (HLM) for the analysis because of the hierarchical nature of the data, with fatigue reports nested within years (33). HLM models individual growth using Ordinary Least Squares (OLS) regression estimates and variations between individuals using maximum likelihood estimates. HLM is designed to estimate parameters despite the potentially biasing effects of individuals contributing multiple observations $(33,34,38,40)$.

Changes in fatigue over time are modeled at two levels. At Level 1 (within individuals), the unit of analysis is the year. This level consists of repeated observations of individuals over time (years). The following equation is adapted from Bryk and Raudenbush (32) to describe the linear growth curve for this analysis: 


$$
\mathrm{Y}_{\mathrm{ti}}=\pi_{0 i}+\pi_{l i} \mathrm{a}_{t i}+\mathrm{e}_{t i}
$$

for $\mathrm{i}=1 \ldots N$ individuals and $\mathrm{Y}_{\mathrm{ti}}=$ fatigue score for person $\mathrm{i}$ at time $\mathrm{t}$

$\pi_{0 \mathrm{i}}=$ the intercept parameter indicates the estimated fatigue level for each person in the 1 st year of this study, and $\pi_{1 i}=$ the linear slope parameter indicates the growth rate for each individual for each year

$\mathrm{a}_{\mathrm{ti}}=$ the measure of time (in this study, the year of the interview for individual i)

$\mathrm{e}_{\mathrm{ti}}=$ the error, usually assumed to be independently and normally distributed with a mean of 0 and a constant variance $\sigma^{2}$

At Level 2 (between individuals), the unit of analysis is the individual. The second level coefficients describe how variations in unchanging characteristics of the individual, such as having a history of $\mathrm{AD}$, can explain differences in intercepts (initial fatigue level) and slopes (fatigue trajectory coefficients) between individuals. We used the HLM4 (Version 4) program to generate estimates of the variance and covariance components of the growth-curve model and the estimates of the $\beta_{0 q}$ coefficients (41).

The following equations describe the Level 2 relations (32):

$$
\begin{gathered}
\pi_{0 i}=\beta_{00}+\sum_{q=1}^{Q_{0}} \beta_{0 q} X_{0 q i}+r_{o i} \\
\pi_{1 i}=\beta_{10}+\sum_{Q=1}^{Q_{1}} \beta_{1 q} X_{1 q i}+r_{1 i}
\end{gathered}
$$

$\mathrm{X}_{q i}=$ measures of characteristics at the person level for each individual i

$\beta_{0 q}=$ the effects of the characteristics on the slope and intercept parameters

$\mathrm{r}_{o i}$ and $\mathrm{r}_{1 i}=$ error terms that are assumed to be uncorrelated with the characteristics and are multivariate normally distributed with means of 0 . The error terms represent unmeasured characteristics of individual $i$ that do not change over time.

\section{Steps in the Analysis}

We begin with a series of descriptive analyses to determine the prevalence of past and current $\mathrm{AD}$, as well as the general pattern of change in fatigue among the study participants. This step is essential because few theories exist regarding the likely shape of the fatigue trajectory (42). In the next step, we estimate a baseline growth-curve model with time (mean growth rate) as the only independent variable. This model estimates individual OLS regression equations for all 415 participants. The baseline growth model also provides an estimate of the average fatigue level in the 1st year of the study and the average rate of change in fatigue from year to year, across all individuals. The 415 intercepts and slopes from this baseline growth model become the primary outcomes of interest to explain in the remaining models. ${ }^{1}$

Because the shape of the fatigue trajectory is unknown, we tested the possibility that a nonlinear model of change more adequately fits the data than do linear models. We tested a nonlinear growth model by including time squared in this baseline model $(34,36,38,40,43)$ that tests for a curvilinear pattern in which fatigue increases quickly at first and then more slowly in later years. The inclusion of this variable did not improve the fit of the model; therefore, we maintain the more parsimonious linear model throughout the analyses.

We next tested the importance of having had an $\mathrm{AD}$ on the fatigue trajectory coefficients. In the specific AD model, dummy variables indicating whether an individual had a history of a specific disorder (MD, GAD, or both [comorbidity]) were used to explain differences in initial fatigue status and the fatigue growth rate between individuals. In the combined AD model, a single dummy variable indicating whether an individual had a history of any disorder was used to explain differences in initial fatigue status and the fatigue growth rate between individuals.

Two rival explanations for the expected differences in fatigue were tested next. The first is that the duration of time with RA explains differences in the fatigue trajectory (4). Therefore, we included in the model years since diagnosis of RA at the start of the study. The second explanation is that a history of AD may be a risk factor for higher current fatigue only when current distress levels are elevated $(3,6,44)$. To test the relation between current distress and fatigue, distress was measured in two ways in the same model $(39,45,46)$. At the within-individual level, current distress was measured as deviations from each individual's own mean CES-D score across the 7 years. At the between-individual level, current distress was measured as average CES-D scores aggregated across the 7 years of the study. Thus, we asked how much of the variation in fatigue was due to changes in distress within individuals year to year and how much was due to differences between individuals in aggregate mean distress. ${ }^{2}$

\section{RESULTS}

Table 1 shows the distribution of lifetime and current diagnoses across study participants. Those meeting full criteria for both MD and GAD are not combined in a separate comorbid cat-

${ }^{1}$ Because the time period for the study is arbitrary (1989-1995), the 1st year of the study has no special meaning. Therefore, the choice of the 1st year of the study as an "index year" in models presented in Table 2 is arbitrary (the intercept indicates fatigue in the 1st year of the study because the year variable is coded as zero for the 1st year). We, therefore, tested models with both the 4th year (middle) and the last year (separately) coded as zero to see if the particular year chosen as the index influences the results. The coefficients change very little, with no substantive or statistical consequences for the conclusions of the analysis. We, therefore, proceed to the second level of analysis using the coefficients estimated by the linear growth-curve model (Table 2).

${ }^{2}$ In the final full model, the intercept, $\beta_{00}$, indicates fatigue scores in the 1st year of the study for newly diagnosed people without a history of $\mathrm{AD}$ and with average (across people) distress scores. 
egory in this table, and current diagnoses are not included in the count of lifetime diagnoses. Six percent of the sample met criteria for current $\mathrm{MD}$, whereas $15 \%$ met criteria for lifetime depression. Five percent met criteria for current GAD, and $4 \%$ met lifetime criteria. Nearly 20 years had elapsed since the first AD episode for those with a history of GAD, whereas only 7 years had elapsed for those with MD. For most participants, affective events occurred years prior to the diagnostic interview, and for $37 \%$, the first episode occurred prior to the onset of RA.

The baseline fatigue growth-curve model in Table 2 reveals that on average, patients reported initial fatigue scores in the middle range of the scale $\left(\beta_{00}=\right.$ mean initial fatigue $=49.68$, $95 \%$ confidence interval $=47.11-52.25)$, with scores increasing by $.5 \%$ per year $\left(\beta_{01}=\right.$ mean growth rate $\left.=0.51, p=.026\right)$. The significant coefficient for mean growth rate indicates that on average, fatigue increases over time. The chi-square value for the

TABLE 1

The Distribution of Lifetime and Current Diagnoses Across Study Participants

\begin{tabular}{lrc}
\hline Affective Diagnosis & $\%$ & $n$ \\
\hline Current major depression & 6 & 26 \\
Lifetime major depression & 15 & 61 \\
Current Generalized Anxiety Disorder & 5 & 21 \\
Lifetime Generalized Anxiety Disorder & 4 & 17 \\
\hline
\end{tabular}

variance component is significant for both mean initial fatigue $\left(\chi^{2}=1,563.9, p=.0001\right)$ and mean growth rate $\left(\chi^{2}=631.33, p=\right.$ $.001)$. Therefore, we can infer that differences exist among the 415 people in their initial fatigue levels and in the rate of change in fatigue over time. When the total variance was partitioned into components, a little over one half was due to differences between individuals (523.26, or $56 \%$ of the variance), with the remainder due to within-individual variance in fatigue over time.

Including dummy variables indicating a history of a specific $\mathrm{AD}$ (MD, GAD, or comorbidity) reduced the variance by $3 \%$ (see Table 2, Specific AD model). In other words, $3 \%$ of the true between-person variance (which itself was $56 \%$ of the total variance) in initial fatigue is accounted for by history of AD status. Comorbidity was not associated with higher fatigue scores $\left(\beta_{03}=8.19, p=.226\right)$. Although individuals with a history of GAD reported average levels of initial fatigue that were comparable to those of individuals with a history of MD (GAD: $\beta_{02}=$ $10.98, p=.094$; MD: $\left.\beta_{01}=10.92, p=.004\right)$, the coefficient was significantly different only for those in the latter group.

When patients with a history of $\mathrm{AD}$ were combined into one group, the results changed little (Table 2, Combined AD model). Although initial fatigue was higher for those in the affective history group $(47.31+10.46=57.77)$, there were no differences in the slopes or rate of change in fatigue between the two groups $\left(\beta_{11}=-.29, p=.605\right)$. On average, changes in fatigue tended to be smaller year to year for the affective history group compared to the no-history group.

TABLE 2

Coefficients of the Hierarchical Linear Models of Fatigue Trajectories, Baseline and Affective Disorder Models, for Rheumatoid Arthritis (1989-1995)

\begin{tabular}{|c|c|c|c|c|}
\hline Fixed Effects & Coefficient & $S E$ & $t$ Ratio & $p$ \\
\hline \multicolumn{5}{|l|}{ Baseline fatigue growth-curve model } \\
\hline Mean initial fatigue $\left(\beta_{00}\right)$ & 49.68 & 1.31 & 37.94 & .0001 \\
\hline Mean growth rate $\left(\beta_{01}\right)$ & 0.51 & 0.23 & 2.23 & .0260 \\
\hline \multicolumn{5}{|l|}{ Specific AD model } \\
\hline \multicolumn{5}{|c|}{$\begin{array}{l}\text { Model to explain variance in initial fatigue level estimated } \\
\text { within individuals (intercepts, } \pi_{0 i} \text { ) }\end{array}$} \\
\hline No history $\left(\beta_{00}\right)$ & 47.31 & 1.47 & 32.10 & .0001 \\
\hline $\operatorname{MD}\left(\beta_{01}\right)$ & 10.92 & 3.69 & 2.96 & .0040 \\
\hline $\operatorname{GAD}\left(\beta_{02}\right)$ & 10.98 & 6.57 & 1.67 & .0940 \\
\hline Comorbid (combined MD+GAD) $\beta_{03}$ & 8.19 & 6.76 & 1.21 & .2260 \\
\hline \multicolumn{5}{|c|}{$\begin{array}{l}\text { Model to explain variance in growth rate estimated within } \\
\text { individuals (years, } \pi_{1 i} \text { ) }\end{array}$} \\
\hline No history $\left(\beta_{10}\right)$ & 0.58 & 0.26 & 2.21 & .0270 \\
\hline $\operatorname{MD}\left(\beta_{11}\right)$ & -0.57 & 0.66 & -0.87 & .3850 \\
\hline $\operatorname{GAD}\left(\beta_{12}\right)$ & 1.33 & 1.17 & 1.14 & .2560 \\
\hline Comorbid (combined MD+GAD) $\beta_{13}$ & -0.91 & 1.20 & -0.76 & .4480 \\
\hline \multicolumn{5}{|c|}{ Combined AD model } \\
\hline \multicolumn{5}{|c|}{$\begin{array}{l}\text { Model to explain variance in initial fatigue level estimated } \\
\text { within individuals (intercepts, } \pi_{0 i} \text { ) }\end{array}$} \\
\hline No history $\left(\beta_{00}\right)$ & 47.31 & 1.47 & 32.17 & .0001 \\
\hline History of $\mathrm{AD}\left(\beta_{01}\right)$ & 10.46 & 3.09 & 3.39 & .0010 \\
\hline \multicolumn{5}{|c|}{$\begin{array}{l}\text { Model to explain variance in growth rate estimated within } \\
\text { individuals (years, } \pi_{2 I} \text { ) }\end{array}$} \\
\hline No history $\left(\beta_{10}\right)$ & 0.58 & 0.26 & 2.21 & .0270 \\
\hline History of $\mathrm{AD}\left(\beta_{11}\right)$ & -0.29 & 0.55 & -0.52 & 6050 \\
\hline
\end{tabular}

Note. $\mathrm{AD}=$ affective disorder $; \mathrm{MD}=$ major depression $; \mathrm{GAD}=$ Generalized Anxiety Disorder. 
We next tested the possibility that some of the variance in intercepts and slopes might be due to length of time living with RA up to the start of the study. There was no support for the "time with RA" explanation for the variations in fatigue; neither the intercepts $\left(\beta_{02}=0.03, p=.83\right)$ nor the slopes $\left(\beta_{12}=-0.00, p\right.$ $=.68)$ were associated with differences in length of time with RA (Table 3, Full model).

In addition, we tested whether changes in current distress, or average aggregate distress, mediated the relation between a history of AD and the fatigue trajectory. We included two variables in the analysis. The first variable tested the relation between changes in current distress and fatigue within individuals (see Table 3, Model for distress to fatigue slope ...). The second variable tested the relation between average aggregate distress (see Table 3, Mean aggregate distress score) and fatigue between individuals. Within individuals, the average coefficient for the distress-fatigue slope was positive (Table 3, Full Model: $\left.\beta_{10}=1.02, p=.001\right)$, indicating that on average, increases in distress were associated with increases in fatigue among the study participants. For a unit change in distress, fatigue increased by $1 \%$. The variance around the average slope (1.02) is $0.46(S D=$ $0.69)$. Therefore, for an individual whose slope is $1 S D$ above this mean, the slope is 1.71 , or more than one half an additional percentage increase in fatigue. CES-D scores explained $11 \%$ of the within-individual variance in fatigue compared to the baseline model. Examining the data between individuals, we found that higher mean aggregate distress scores were associated with higher initial fatigue levels $\left(\beta_{03}=1.79, p=.001\right)$, but a smaller distress-fatigue slope $\left(\beta_{13}=-0.03, p=.001\right)$. Thus, whereas the average initial fatigue score for those with no history and average distress was 48.70, a person with distress just 4 points higher than the average on the CES-D scale would have an average fatigue of $55.94((4 X 1.79)+48.70=55.94)$. Mean aggregate distress scores were not associated with a different rate of change (growth) in fatigue over time $\left(\beta_{23}=-0.02, p=.44\right)$. Mean aggregate distress scores reduced the variance between individuals ( $56 \%$ of the total variance) by $40 \%$.

Because the coefficient for history of $\mathrm{AD}$ was no longer significant in the final model that included distress, we tested a model in which mean aggregate distress mediates the association between a history of AD and current fatigue. To qualify as a mediating variable, the relations among mean aggregate distress, history of $\mathrm{AD}$, and fatigue must meet three conditions (47). First, having a history of AD must be associated with higher mean aggregate distress. We used a simple analysis of variance model to test this association. Mean aggregate distress scores were between 4 and 12 units higher for those with an affective history $(F=21.26, p=.0001, d f=3)$. Scheffé's tests revealed that distress scores for patients with each disorder were higher than those with no disorder. Second, an AD history must be associated with fatigue. The initial significant association between a history and fatigue in the combined AD model (Table 3; $\left.\beta_{01}=10.46, p=.001\right)$ meets this condition. Third, mean aggregated distress must be associated with fatigue and should reduce the initial association between a history and fatigue. In the full model (Table 3), mean aggregated distress is associated with fatigue $\left(\beta_{03}=1.79, p=.0001\right)$, and when this variable is included in the analysis, the association between a history of AD and fatigue is substantially reduced and is no longer statistically significant $\left(\beta_{01}=-.69, p=.80\right)$. This pattern of findings indicates that a history of $\mathrm{AD}$ is associated with higher levels of distress aggregated over a full 7 years, and higher levels of aggregate

TABLE 3

Coefficients of the Hierarchical Linear Models of Fatigue Trajectories, Baseline and Affective Disorder Models, for Rheumatoid Arthritis Patients

\begin{tabular}{|c|c|c|c|c|}
\hline Fixed Effects & Coefficient & $S E$ & t Ratio & $p$ \\
\hline \multicolumn{5}{|l|}{ Full model } \\
\hline \multicolumn{5}{|l|}{$\begin{array}{l}\text { Model to explain variance in initial fatigue level } \\
\text { estimated within individuals (intercepts, } \pi_{0 i} \text { ) }\end{array}$} \\
\hline No history, new RA Dx, average distress $\left(\beta_{00}\right)$ & 48.70 & 1.79 & 27.21 & .0001 \\
\hline History of affective disorder $\left(\beta_{01}\right)$ & -.69 & 2.75 & -0.25 & .8030 \\
\hline Years with RA diagnosis at study start $\left(\beta_{02}\right)$ & 0.03 & 0.12 & 0.22 & .8270 \\
\hline Mean aggregate distress score $\left(\beta_{03}\right)$ & 1.79 & 0.14 & 12.64 & .0001 \\
\hline \multicolumn{5}{|l|}{$\begin{array}{l}\text { Model for distress to fatigue slope estimated within } \\
\text { individuals }\left(\beta_{1 i}\right)\end{array}$} \\
\hline No history, new RA Dx, average distress $\left(\beta_{10}\right)$ & 1.02 & 0.13 & 7.87 & .0001 \\
\hline History of affective disorder $\left(\beta_{11}\right)$ & 0.15 & 0.17 & 0.86 & .3920 \\
\hline Years with RA diagnosis at study start $\left(\beta_{12}\right)$ & -0.00 & 0.01 & -0.41 & 6780 \\
\hline Mean aggregate distress score $\left(\beta_{13}\right)$ & -0.03 & 0.01 & -3.38 & .0010 \\
\hline \multicolumn{5}{|l|}{$\begin{array}{l}\text { Model to explain variance in growth rate estimated } \\
\text { within individuals (years, } \beta_{2 \mathrm{I}} \text { ) }\end{array}$} \\
\hline No history, new RA Dx, average distress $\left(\beta_{20}\right)$ & 0.36 & 0.36 & 2.44 & .0150 \\
\hline Has an affective disorder $\mathrm{Hx}\left(\beta_{21}\right)$ & -0.18 & 0.56 & -0.32 & .7490 \\
\hline Years with RA diagnosis at study start $\left(\beta_{22}\right)$ & -0.01 & 0.02 & -0.18 & .8570 \\
\hline Mean aggregate distress score $\left(\beta_{23}\right)$ & -0.02 & 0.03 & -0.77 & .4400 \\
\hline
\end{tabular}

Note. Within individual: Time and distress. Between individual: Affective disorder status, Mean distress score across the study, and length time with an RA diagnosis (in years) at the start of the study period. $\mathrm{RA}=$ rheumatoid arthritis; $\mathrm{Dx}=$ diagnosis; $\mathrm{Hx}=$ history. 
distress are associated with higher levels of fatigue but a smaller distress-fatigue slope.

\section{DISCUSSION}

Our study shows the importance of examining both the history of $\mathrm{AD}$ and the current level of distress when explaining the experience of fatigue over time among patients with RA. We found that individuals meeting $D S M-I V$ criteria for a history reported levels of fatigue in the 1 st year of the study that were higher and that remained higher over the entire study period compared to those without a history of AD. This finding emerged despite the fact that, in most cases, the episode predated the 1st year of the study, and in many cases occurred as much as 30 years before the diagnostic interview. We also found, however, that higher levels of fatigue among those with an AD history is, at least in part, a function of enduring levels of distress.

The temporal design of the study provided a unique opportunity to explore the experience of RA and major AD over time. For instance, our data show that the first episodes of GAD and MD appeared at ages that are similar to those found in community studies (31). Likewise, we found rates of both lifetime and current GAD and MD in our sample that are approximately the same as those found in community samples, where $5 \%$ to $9 \%$ of women report current $\mathrm{MD}, 3 \%$ report current $\mathrm{GAD}, 10 \%$ to $25 \%$ of women report lifetime $\mathrm{MD}$, and $5 \%$ report lifetime GAD (31). Thus, these two major ADs appear as "on-time" and expected events rather than as events that occur in a cause or effect relation with the onset of RA. In addition, we were able to show how fatigue changes over time. We found that within individuals, levels of fatigue increase slowly over time and in a linear fashion. People with a history of AD have higher initial fatigue (10\% higher), but their fatigue does not worsen at a faster rate over time. In fact, changes in fatigue tended to be smaller year to year for this group. They start with higher levels of fatigue and continue to report higher levels of fatigue over time. Finally, we found that within individuals, changes in distress from year to year are associated with changes in fatigue. However, people with higher levels of distress averaged over the study period had smaller distress-fatigue slopes. This suggests that for individuals with higher overall distress, fatigue is higher overall but is less reactive to changes in distress year to year.

These findings extend our earlier work demonstrating that fatigue, a common and debilitating symptom of RA, is linked to a history of AD. The link is not trivial, as our findings suggest that nearly $20 \%$ of RA patients are at risk for levels of fatigue that are a full $10 \%$ higher than those without a history, and the higher levels persist over 7 years. The relevance of affective history for patients with RA joins a small but growing literature showing the lifetime vulnerability for disability (9), chronic pelvic pain (14), the persistence of fatigue in chronic fatigue syndrome (10), the risk of coronary artery disease (12), and readmission for unstable angina (13), among people with both an AD history and other medical conditions.

These findings are important because they point out the far-reaching effects of affective history on the quality of life of individuals over time. To the extent that fatigue in RA contrib- utes to increased utilization of rheumatology services (4), as well as work disability (44), early treatment could result in savings to individuals and society. These findings also suggest that sustained distress, even in the absence of major AD, may also warrant intervention.

Our findings also demonstrate the importance of examining both within-person and between-person associations before drawing conclusions regarding the relation between fatigue and distress. Within individuals, changes in distress and changes in fatigue were positively related. However, fatigue was less reactive to distress among patients experiencing more distress (more likely to be those with a history). Thus, patients with high levels of distress and high levels of fatigue do not necessarily experience distress-contingent fatigue (or fatigue-contingent distress).

Future studies should explore other mechanisms such as stable personality characteristics (19) and altered biochemical processes $(16,17)$ that would help explain higher levels of either perceived or actual fatigue. Our understanding of the experience of fatigue among those with past $\mathrm{AD}$ and current high distress would also be enhanced with the use of a multidimensional measure of fatigue. Although we had only a single indicator of fatigue in this study, in a follow-up study from the same panel, we found group differences in fatigue of the same magnitude and in the same direction for both our single item indicator and Belsia's Multidimensional Assessment of Fatigue Scale (3). In addition, we found a high correlation $(r=.69)$ between the two measures. Thus, the group effect is robust across both the single item and the multidimensional indicator of fatigue. However, further insights into the nature of the differences in fatigue reported between those with and without a history of AD awaits future studies using a multidimensional measure.

\section{REFERENCES}

(1) Cash JM, Wilder RL: Neurobiology and inflammatory arthritis [Review]. Bulletin of Rheumatic Disease. 1992, 41:1-3.

(2) Crosby LJ: Factors which contribute to fatigue associated with rheumatoid arthritis. Journal of Advanced Nursing. 1991, 16:974-981.

(3) Belza BT: Fatigue in rheumatoid arthritis: Conditions, strategies, and consequences. Arthritis Care and Research. 1990, 3:65-70.

(4) Belza BT, Henke C, Yelin EH, Epstein WV, Gilliss CL: Correlates of fatigue in older adults with rheumatoid arthritis. Nursing Research. 1993, 42:93-99.

(5) Smedstad LM, Moum T, Vaglum P, Kvien TK: The impact of early rheumatoid arthritis on psychological distress. A comparison between 238 patients with RA and 116 matched controls. Scandinavian Journal of Rheumatology. 1996, 25:377-382.

(6) Stone AA, Broderick JE, Porter LS, Kaell AT: The experience of rheumatoid arthritis pain and fatigue: Examining momentary reports and correlates over one week. Arthritis Care and Research. 1997, 10:185-193.

(7) Katz PP: The stresses of rheumatoid arthritis: Appraisals of perceived impact and coping efficacy. Arthritis Care and Research. 1998, 11:9-22. 
(8) Huyser BA, Parker JC, Thoreson R, et al.: Predictors of subjective fatigue among individuals with rheumatoid arthritis. Arthritis and Rheumatism. 1998, 41:2230-2237.

(9) Armenian HK, Pratt LA, Gallo J, Eaton WW: Psychopathology as a predictor of disability: A population-based follow-up study in Baltimore, Maryland. American Journal of Epidemiology. 1998, 148:269-275.

(10) Clark MR, Katon W, Russo J, et al.: Chronic fatigue: Risk factors for symptom persistence in a $21 / 2$-year follow-up study. American Journal of Medicine. 1995, 98:187-195.

(11) Fifield JF, Tennen H, Reisine S, McQuillan J: Depression and the long-term risk of pain, fatigue and disability in patients with rheumatoid arthritis. Arthritis and Rheumatism. 1998, 41:1851-1857.

(12) Ford DE, Mead LA, Chang MD, et al.: Depression is a risk factor for coronary artery disease in men. Archives of Internal Medicine. 1998, 158:1422-1426.

(13) Frasure-Smith N, Lesperance F, Talajic M: The impact of negative emotions on prognosis following myocardial infarction: Is it more than depression? Health Psychology. 1995, 14:388-398.

(14) Walker EA, Katon WJ, Hanson J, et al.: Psychiatric diagnoses and sexual victimization in women with chronic pelvic pain. Psychosomatics. 1995, 36:531-540.

(15) Cohen S, Rodriguez MS: Pathways linking affective disturbances and physical disorders. Health Psychology. 1995, 14:374-380.

(16) Post RM: Transduction of psychosocial stress into the neurobiology of recurrent affective disorder. American Journal of Psychiatry. 1992, 149:999-1010.

(17) Sheline YI, Sanghavi M, Mintun MA, Gado MH: Depression duration but not age predicts hippocampal volume loss in medically healthy women with recurrent major depression. Journal of Neuroscience. 1999, 19:5034-5043.

(18) Rush AJ, Erman MK, Giles DE, et al.: Polysomnographic findings in recently drug-free and clinically remitted depressed patients. Archives of General Psychiatry. 1986, 43:878-884.

(19) Shea MT, Leon AC, Mueller TI, et al.: Does major depression result in lasting personality change? American Journal of Psychiatry. 1996, 153:1404-1410.

(20) Larsen RJ: Neuroticism and selective encoding and recall of symptoms: Evidence from a combined concurrent-retrospective study. Journal of Personality and Social Psychology. 1992, 62:480-488.

(21) Ropes MW, Bennett GA, Cobb S, Jacox R, Jessar RA: 1958 revision of diagnostic criteria for rheumatoid arthritis. Bulletin of Rheumatic Disease. 1958, 9:175-176.

(22) Yelin E, Henke C, Epstein W: The work dynamics of the person with rheumatoid arthritis. Arthritis and Rheumatism. 1987, 30:507-512.

(23) Bucholz KK, Cadoret R, Cloninger CR, et al.: A new, semi-structured sychiatric interview for use in genetic linkage studies: A report on the reliability of the SSAGA. Journal of Studies on Alcohol. 1994, 55:149-158.

(24) Robins LN, Helzer JE: Diagnostic Interview Schedule (DIS) Version III-A. St. Louis, MO: Washington University School of Medicine, Department of Psychiatry, 1985.

(25) Wells KB, Burnam MA, Leake B, Robins LN: Agreement between face-to-face and telephone-administered versions of the depression section of the NIMH Diagnostic Interview Schedule. Journal of Psychiatric Research. 1988, 22:207-220.
(26) Hesselbrock M, Easton C, Bucholz KK, Schuckit M, Hesselbrock V: A validity study of the SSAGA - a comparison with the scan. Addiction. 1999, 94:1361-1370.

(27) Meenan RF, Anderson JJ, Kazis LE, et al.: Outcome assessment in clinical trials: Evidence for the sensitivity of a health status measure. Arthritis and Rheumatism. 1984, 27:1344-1352.

(28) Radloff L: The CES-D scale: A self-report depression scale for research in the general population. Applied Psychological Measurement. 1977, 1:385-401.

(29) Hesselbrock MN, Hesselbrock VM, Tennen H, Meyer RE, Workman KL: Methodological considerations in the assessment of depression in alcoholics. Journal of Consulting Clinical Psychology. 1983, 51:399-405.

(30) Blaney PH: Affect and memory: A review. Psychological Bulletin. 1986, 99:229-246.

(31) American Psychiatric Association: Diagnostic and Statistical Manual of Mental Disorders (4th ed.). Washington, DC: American Psychiatric Association, 1994.

(32) Bryk AS, Raudenbush SW: Hierarchical Linear Models: Applications and Data Analysis Methods. Newbury Park, CA: Sage, 1992.

(33) Brown C, Schulberg HC, Madonia MJ, Shear MK, Houck MS: Treatment outcomes for primary care patients with major depression and lifetime anxiety disorders. American Journal of Psychiatry. 1996, 153:1293-1300.

(34) Karney BR, Bradbury TN: Assessing longitudinal change in marriage: An introduction to the analysis of growth curves. Journal of Marriage and the Family. 1995, 57:1091-1108.

(35) Cherlin AJ, Chase-Landsdale PL, McRae C: Effects of parental divorce on mental health throughout the life course. American Sociological Review. 1998, 63:239-249.

(36) Chou CP, Bentler PM, Pentz MA: Comparisons of two statistical approaches to study growth curves: The multilevel model and the latent curve analysis. Structural Equation Modeling. 1998, 5:247-266.

(37) Davila J, Karney BR, Bradbury TN: Attachment change processes in the early years of marriage. Journal of Personality and Social Psychology. 1999, 76:738-802.

(38) Osgood WD, Smith GL: Applying hierarchical linear modeling to extended longitudinal evaluations: The Boys Town follow-up study. Evaluation Review. 1995, 19:3-38.

(39) Schwartz JE, Stone AA: Strategies for analyzing ecological momentary assessment data. Health Psychology. 1998, 17:6-16.

(40) Snijders T: Analysis of longitudinal data using the hierarchical linear model. Quality \& Quantity. 1996, 30:405-426.

(41) Bryk AS, Raudenbush SW, Congdon Jr. RT: HLM: Hierarchical Linear and Nonlinear Modeling With the HLM/2L and HLM/3L Programs. Chicago, IL: Scientific Software International, 1994.

(42) Diggle P, Liang KY, Zeger SL: Analysis of Longitudinal Data. New York: Oxford University Press, 1994.

(43) Allison PD: Using panel data to estimate the effects of events. Sociological Methods and Research. 1994, 23:174-199.

(44) Kreft IG, de Leeuw J, Aiken LS: The effect of different forms of centering in hierarchical linear models. Multivariate Behavioral Research. 1995, 30:1-21.

(45) Wolfe F, Hawley D, Wilson K: The prevalence and meaning of fatigue in rheumatic disease. Journal of Rheumatology. 1996, 23:1407-1417. 
(46) Horney J, Osgood DW, Marshall IH: Criminal careers in the short-term: Intra-individual variability in crime and its relation to local life circumstances. American Sociological Review. 1995, 60:655-673.
(47) Baron RM, Kenny DA: The moderator-mediator variable distinction in social psychological research: Conceptual, strategic, and statistical considerations. Journal of Personality and Social Psychology. 1986, 51:1173-1182. 